\title{
Stability of the southern European border of Echinococcus multilocularis in the Alps: evidence that Microtus arvalis is a limiting factor
}

\author{
DIOGO GUERRA ${ }^{1}$, DANIEL HEGGLIN ${ }^{1}$, LUCA BACCIARINI ${ }^{2}$, \\ MANUELA SCHNYDER ${ }^{1}$ and PETER DEPLAZES ${ }^{1} *$ \\ ${ }^{1}$ Institute of Parasitology, University of Zurich, Winterthurerstrasse 266a, CH-8057 Zurich, Switzerland \\ ${ }^{2}$ Cantonal Veterinary Office, Via Dogana 16, CH-6500 Bellinzona, Switzerland
}

(Received 6 February 2014; revised 31 March 2014; accepted 1 April 2014; first published online 16 fune 2014)

SUMMARY

The known range of the zoonotic fox tapeworm Echinococcus multilocularis has expanded since the 1990s, and today this parasite is recorded in higher abundances throughout large parts of Europe. This phenomenon is mostly attributed to the increasing European fox populations and their invasion of urban habitats. However, these factors alone are insufficient to explain the heterogeneous distribution of the parasite in Europe. Here, we analysed the spatial interrelationship of E. multilocularis with the known distribution of seven vole species in Ticino, southern Switzerland. Among 404 necropsied foxes (1990-2006) and 79 fox faecal samples (2010-2012), E. multilocularis was consistently found in the north of the investigated area. No expansion of this endemic focus was recorded during the 22 years of the study period. This stable endemic focus is coincident with the known distribution of the vole species Microtus arvalis but not, or only partly, with the distribution of the other autochthonous vole species. Our results give evidence that this vole species plays a crucial role in the maintenance of the parasite's life cycle and that its absence could be a limiting factor for the spread of E. multilocularis in this region.

Key words: distribution, Echinococcus multilocularis, fox, Microtus arvalis, rodents, Switzerland.

\section{INTRODUCTION}

Echinococcus multilocularis is a small zoonotic tapeworm whose life cycle is based on a predator-prey interaction. In Europe, the red fox (Vulpes vulpes) is the main definitive host, harbouring the parasite's adult stage in the small intestine. Different rodents are infected upon ingesting eggs from a contaminated environment and the subsequent development of an alveolar metacestode in the liver (Eckert et al. 2011). Arvicolids, especially the common vole (Microtus arvalis) and the water vole (Avvicola scherman, former Arvicola terrestris), are considered as the main intermediate hosts in Europe (Houin et al. 1982; Stieger et al. 2002; Reperant et al. 2009).

Echinococcus multilocularis is distributed over large regions throughout the northern hemisphere (Eckert et al. 2011). Its historical endemic area in Europe was circumscribed to eastern France, Switzerland, southern Germany and western Austria (Rausch, 1967), but during the last three decades, E. multilocularis infections in foxes have been reported far outside this region from western France (Combes et al. 2012) to Romania (Sikó et al. 2011), Ukraine (Kharchenko et al. 2008), the Baltic countries (Moks

* Corresponding author: Institute of Parasitology, Winterthurerstrasse 266a, CH-8057 Zurich, Switzerland. E-mail: deplazesp@access.uzh.ch et al. 2005; Bružinskaitè et al. 2007) and as far north as southern Sweden (Lind et al. 2011). Such new records not necessarily document a real spread as the detection probability in low endemic areas strongly depends on the sampling effort. In Sweden, for example, 2985 foxes shot in 2011 had to be analysed in order to detect three positive animals in three very distinct foci (Lind et al. 2011). Therefore, it is hard to judge whether these records reproduce an expansion or just the first findings in very low endemic areas. However, existing data clearly show that E. multilocularis in foxes became at least more abundant over a large part of Europe during the last two decades (Sreter et al. 2003; Combes et al. 2012).

In this study, the southern border of $E$. multilocularis in Europe is the focus (Fig. 1). The most southern E. multilocularis records in foxes in France are reported in the historically endemic department of Cantal (Deblock et al. 1988) and recently further east, in the department of Savoie (Combes et al. 2012). South of the Alps, infected foxes have already been recorded in the cantons of Ticino (Ewald, 1993) and Grisons, Switzerland (Tanner et al. 2006), and in the very northern part of Italy, in Bolzano and Trento provinces (Manfredi et al. 2002; Casulli et al. 2005). The E. multilocularis endemic areas in northern Italy are adjacent to the Austrian ones, where the parasite seems to be ubiquitously 


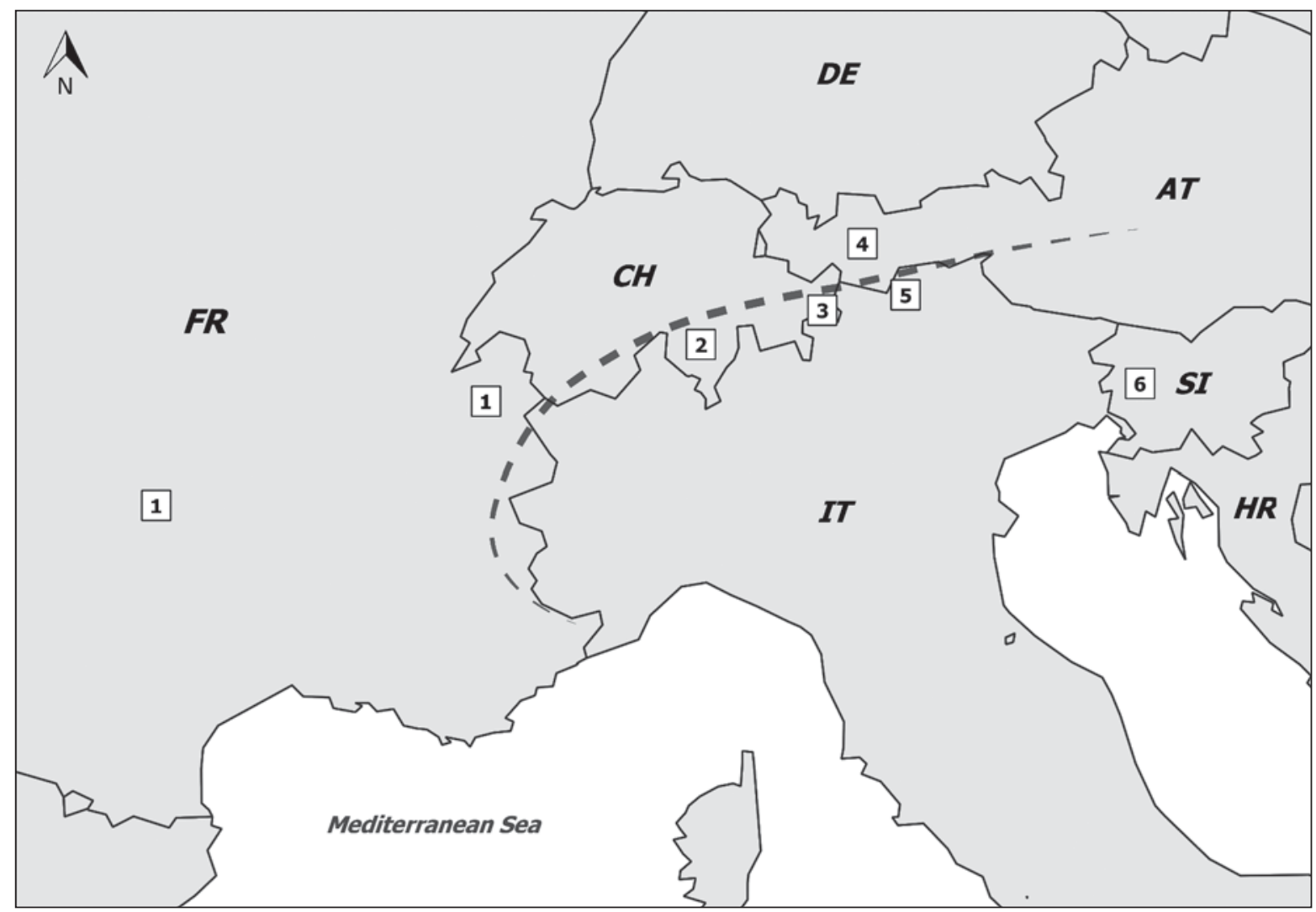

Fig. 1. Distribution of the most southern infections by Echinococcus multilocularis in foxes from the Alps and adjacent regions. AT - Austria; CH - Switzerland; DE - Germany; FR - France; HR - Croatia; IT - Italy; SI - Slovenia. References: 1 - Combes et al. (2012); 2 - Ewald (1993); 3 - Tanner et al. (2006); 4 - Duscher et al. (2006); 5 - Casulli et al. (2005); 6 - Rataj et al. (2010). The dashed line represents the main Alpine divide.

distributed (Duscher et al. 2006). No records exist further south in the Italian peninsula (Di Cerbo et al. 2008; Magi et al. 2009). Towards east and southeast, the parasite is known to be present in Slovenia (Rataj et al. 2010), Hungary (Sreter et al. 2003) and in adjacent areas in north-western Romania (Sikó et al. 2011). No foxes were found infected from the north of Croatia (Rajković-Janje et al. 2002), but the presence of $E$. multilocularis metacestodes is described in $M$. arvalis from the north of Bulgaria (Genov et al. 1980).

As mentioned above, abundance and prevalence of $E$. multilocularis in foxes were shown to have augmented over large areas, e.g. the Netherlands (Takumi et al. 2008) or Germany (Berke et al. 2008; Staubach et al. 2011), respectively. Likewise, a growing incidence is reported for alveolar echinococcosis (AE) in humans. In Switzerland, for example, the incidence of human cases increased 2.5 times between the years 2000-2005 (Schweiger et al. 2007). A tendency in the increase of AE cases was also documented for Austria (Schneider et al. 2013) and France (Said-Ali et al. 2013). The rising numbers of foxes and the urbanization of the E. multilocularis life cycle in Europe have been pointed out as possible causes for the described patterns (Deplazes et al. 2004; Fischer et al. 2005; Schweiger et al. 2007).
In Belgium, on the other hand, no emergence of the parasite was detected in foxes during 1996-2008, although the fox population had considerably increased during the same period (Van Gucht et al. 2010). This suggests that the observed trends for E. multilocularis in Europe are heterogeneous and can only partially be explained by changes in the fox population dynamics.

The spatial dynamics of $E$. multilocularis occurrence and abundance are not well understood and few studies investigated different factors putatively limiting the distribution of this parasite. Mean temperature and humidity, for example, have an impact on egg survival in the environment (Veit et al. 1995) and may affect the transmission potential and the infection of intermediate hosts. However, it has to be considered that the role of these hosts depends not only on their infection rates, but also on the fertility of the larval stages and on the extent by which they are predated by definitive hosts. Moreover, the distribution and abundance of intermediate hosts are likewise expected to be key factors for the establishment and maintenance of the life cycle in a given habitat (Giraudoux et al. 2003; Hansen et al. 2004; Guislain et al. 2008; Raoul et al. 2010). The distribution of rodent species is mainly shaped by the availability of suitable habitats and by climatic factors 
Table 1. Echinococcus multilocularis in foxes $(n=404)$ and fox faecal samples $(n=79)$ from the Canton Ticino (Switzerland) during 1990-2012

\begin{tabular}{|c|c|c|c|c|c|}
\hline Period & $\begin{array}{l}\text { Diagnostic } \\
\text { techniques }^{\mathrm{a}}\end{array}$ & $N$ total & $\begin{array}{l}N \text { endemic } \\
\text { area }\end{array}$ & $\begin{array}{l}\text { E. multilocularis prevalence } \\
\text { (CI 95\%) endemic area }\end{array}$ & $\begin{array}{l}\text { E. multilocularis prevalence } \\
\text { (CI } 95 \%) \text { non-endemic area }\end{array}$ \\
\hline $1990-1992^{\mathrm{b}}$ & IST & 55 & 15 & $13 \cdot 3(1 \cdot 7-40 \cdot 5)$ & $0 \cdot 0(0 \cdot 0-7 \cdot 2)$ \\
\hline $1993-1994^{\mathrm{c}}$ & IST & 93 & 27 & $7 \cdot 4(0 \cdot 9-24 \cdot 3)$ & $0 \cdot 0(0 \cdot 0-4 \cdot 4)$ \\
\hline 1999-2000 & SCT & 75 & 24 & $4 \cdot 2(0 \cdot 1-21 \cdot 1)$ & $0 \cdot 0(0 \cdot 0-5 \cdot 7)$ \\
\hline $2002-2003$ & SCT & 57 & 47 & $10 \cdot 6(3 \cdot 5-23 \cdot 1)$ & $0 \cdot 0(0 \cdot 0-25 \cdot 9)$ \\
\hline 2005-2006 & $\mathrm{SCT}$ & 124 & 33 & $6 \cdot 1(0 \cdot 7-20 \cdot 2)$ & $0 \cdot 0(0 \cdot 0-3 \cdot 2)$ \\
\hline 2010-2012 & Coprology & 79 & 16 & $6 \cdot 3(0 \cdot 2-30 \cdot 2)$ & $0 \cdot 0(0 \cdot 0-4 \cdot 6)$ \\
\hline
\end{tabular}

a IST - Intestinal Scraping Technique; SCT - Sedimentation and Counting Technique; Coprology - Sieving and flotation technique and molecular identification.

b Ewald (1993).

c Alther (1996).

(Giraudoux et al. 2003, 2013b) as well as by postglacial range expansion (Braaker and Heckel, 2009). Accordingly, a recent study in China demonstrated how key rodent species could be used to describe the distribution ranges of E. multilocularis over large areas (Giraudoux et al. 2013a). However, the distribution of most rodents is rather heterogeneous and rodent community composition can be highly variable over small areas, just like the patchy distribution of E. multilocularis infections in rodents and foxes (Tanner et al. 2006). In the framework of this study, we investigated the long-term spatial dynamics of E. multilocularis on a small scale in the south of Switzerland and analysed how the observed pattern correlates with the known distribution of autochthonous vole species.

\section{MATERIALS AND METHODS}

\section{Study area}

This study was conducted in the Canton of Ticino (southern Switzerland) which has a surface area of approximately $2812 \mathrm{~km}^{2}$. Half of the territory is covered by forest, $30 \%$ by unproductive areas (i.e. mountains, lakes and rivers), $13 \%$ by agricultural areas and $6 \%$ by human infrastructures (data: Swiss Federal Statistics Office, www.bfs.admin.ch). There is a predominance of an alpine landscape, with deep valleys and high mountains (altitudes range from 200 to $3400 \mathrm{~m}$ ).

There are seven Arvicolid species described in Ticino, which are potential intermediate hosts for E. multilocularis: Arvicola amphibius, Chionomys nivalis, M. arvalis, Microtus multiplex, Microtus savii, Microtus subterraneus and Myodes glareolus (Hausser, 1995).

\section{Samples}

A total of 404 red foxes, obtained from hunters between 1990 and 2006, were analysed. These specimens had been shot in the course of the official hunting seasons and a small percentage $(<2 \%)$ had been found dead (e.g. road killed). Five time periods were studied: 1990-1992 (Ewald, 1993); 1993-1994 (Alther, 1996); 1999-2000; 2002-2003 and 2005-2006 (unpublished results). Sex, age and location were recorded for each animal. Whenever the exact location was not available, the coordinates of the nearest human settlement were used. In order to inactivate taeniid eggs, carcasses were deep-frozen at $-80{ }^{\circ} \mathrm{C}$ for at least 5 days (Eckert et al. 2001). Helminthological investigations were performed either by the Intestinal Scraping Technique (IST) (Eckert et al. 2001) or by the Sedimentation and Counting Technique (SCT) (Hofer et al. 2000) (Table 1).

Based on typical morphological characteristics, prevalence rates of some common intestinal helminths were determined: E. multilocularis (for the period 1990-2006), Taenia spp., Mesocestoides spp., hookworms (Uncinaria spp.) and ascarids (Toxocara spp. and Toxascaris leonina) (for the period 1999-2006 only).

During 2010-2012, 79 fox and 23 dog faecal samples were collected in the same study area. Collection was performed between April and November when snow or grass coverage were lowest. Species identification for faecal samples was based on content, morphology, odour and location (Stieger et al. 2002). Faecal samples were also frozen at $-80^{\circ} \mathrm{C}$ for at least 5 days prior to any analysis. Two grams of each sample were screened for taeniid eggs with a sievingflotation technique (Mathis et al. 1996). DNA extraction from positive samples was performed according to Štefanić et al. (2004) and a multiplex-PCR for taeniid genus identification was used (Trachsel et al. 2007), with the primer pairs described by the authors. Echinococcus multilocularis positive samples were confirmed by sequencing, after purification with a MinElute PCR purification kit (Qiagen, Hilden, Germany). Sequencing was carried out by Synergene Biotech GmbH, Biotech Centre Zurich, Switzerland (www.synergene-biotech.com) and results compared with GenBank nucleotide database (BLAST; www. blast.ncbi.nlm.nih.gov). 


\section{Spatial and statistical analysis}

A map with the coordinates of all carcasses and faecal samples was built using the software QuantumGIS version 1.8.0 Lisboa, http:/qgis.org/. Official Switzerland borders were obtained from the Swiss Federal Office of Topography (www.swisstopo. admin.ch/; version from 1.1.2013).

The Swiss Biological Records Center (CSCF) (http://lepus.unine.ch/carto/) provides cartographical server information on the known distribution of the Swiss fauna. The distribution maps of the different rodent species, which are provided on the base of a $5 \times 5 \mathrm{~km}$ grid, were used for comparisons with the recorded distribution of $E$. multilocularis in foxes.

The endemic area for E. multilocularis was defined by all grid cells where infections of fox origin were recorded and a buffer zone of 1 cell $(5 \times 5 \mathrm{~km})$ around this area therewith accounting for the spatial behaviour of foxes. Fox home-range sizes in different studies on Continental Europe ranged between $0 \cdot 6-9 \cdot 3 \mathrm{~km}^{2}$ (Trewhella et al. 1988; Meia and Weber, 1995). All grid cells outside this area were referred as belonging to a non-endemic area.

As rough indicators of fox predation on rodents, prevalence rates of rodent- and non-rodent-related intestinal helminths were compared between foxes originating from the $E$. multilocularis endemic and non-endemic areas, using the Chi-square test. Statistical analysis was carried out using SPSS 20.0. Significance value was set as $P<0 \cdot 05$.

\section{RESULTS}

Between one and five E. multilocularis positive samples were recorded in foxes in every period studied (Table 1). The periodic prevalence rates in the endemic area ranged between $4 \cdot 2$ and $13 \cdot 3 \%$ and the overall rates were $9 \cdot 5 \%$ (IST; 1990-1994) and $7 \cdot 7 \%$ (SCT; 1999-2006). The occurrence of E. multilocularis in fox faecal samples was $6 \cdot 3 \%$ (2010-2012). The presence of E. multilocularis eggs was detected in one out of just four dog faecal samples from the endemic area. For this faecal sample only, the host species was confirmed by a multiplex-PCR (Nonaka et al. 2009).

All positive $E$. multilocularis samples $(n=13)$ were from an endemic area with approximately $160 \mathrm{~km}^{2}$ in the most northern part of Ticino (Fig. 2), just south of the main Alpine divide. In this area there are two main valleys with north-south orientation that merge further south: Val Leventina in the West and Valle di Blenio in the East (Fig. 2). Most of the positive samples were from Val Leventina and only one from Valle di Blenio. No evident changes in the latitude of the infections were recorded throughout the study periods (Fig. 2). The most southern infected fox was located at latitude $46 \cdot 49^{\circ} \mathrm{N}$ (Decimal degrees,
WGS84) in Val Leventina. The positive dog sample originated from approximately $2 \mathrm{~km}$ southwest from this point.

Analysis of rodent communities revealed that $M$. arvalis is the only species contemporaneously present in the E. multilocularis endemic area and completely absent in the other area (Fig. 3A). Microtus subterraneus was also predominantly recorded in the endemic area, but there are records in two other locations further south (Fig. 3F). The distribution of all other Arvicolids was apparently unrelated to the one of $E$. multilocularis in foxes, including A. amphibius and $M$. savii which were present solely in the non-endemic area.

There was a significantly higher prevalence of Taenia species in the E. multilocularis endemic area (Fig. 4). The prevalence rates of Mesocestoides spp., hookworms and ascarids exhibited no differences between the two investigated areas.

\section{DISCUSSION}

\section{Distribution of E. multilocularis in foxes}

Our results give no evidence for a spread of the distribution of E. multilocularis in Ticino over a 20 -year period. The infected samples were constantly obtained from a very small geographic area and there were no major changes in their latitude that could suggest a southern spread.

The fact that all 258 foxes investigated from southern areas of Ticino were not infected gives strong evidence that the parasite is absent in this region or only occurs occasionally.

The overall E. multilocularis prevalence in foxes from the endemic area in Ticino is much lower compared with hyper-endemic locations north of the Alps, where prevalence rates higher than $30 \%$ have frequently been recorded, e.g. in Switzerland (Brossard et al. 2007; Hegglin et al. 2007; Reperant et al. 2007) or Austria (Duscher et al. 2006). In fact, the prevalence rate is similar to the ones obtained from other alpine regions, such as the Swiss canton of Grisons $(<14 \cdot 3 \%$ ) (Tanner et al. 2006) or the Bolzano and Trento provinces, in northern Italy $(<12.9 \%)$ (Manfredi et al. 2002; Casulli et al. 2005) (Fig. 1). A north-to-south decreasing gradient of the prevalence rates is evident between the highly endemic areas in northern Switzerland and Austria, and adjacent foci in the South. On these three alpine regions, infected foxes exhibit a patchy distribution coincident with specific valleys. In the Canton of Grisons, infected foxes have been found in the Müstair Valley that is in close connection with an Italian valley in Bolzano, where one of the Italian foci is located (Casulli et al. 2009). Since foxes can disperse over large distances (Trewhella et al. 1988; Meia and Weber, 1995), occasional exchanges of parasites between these two areas are likely. 


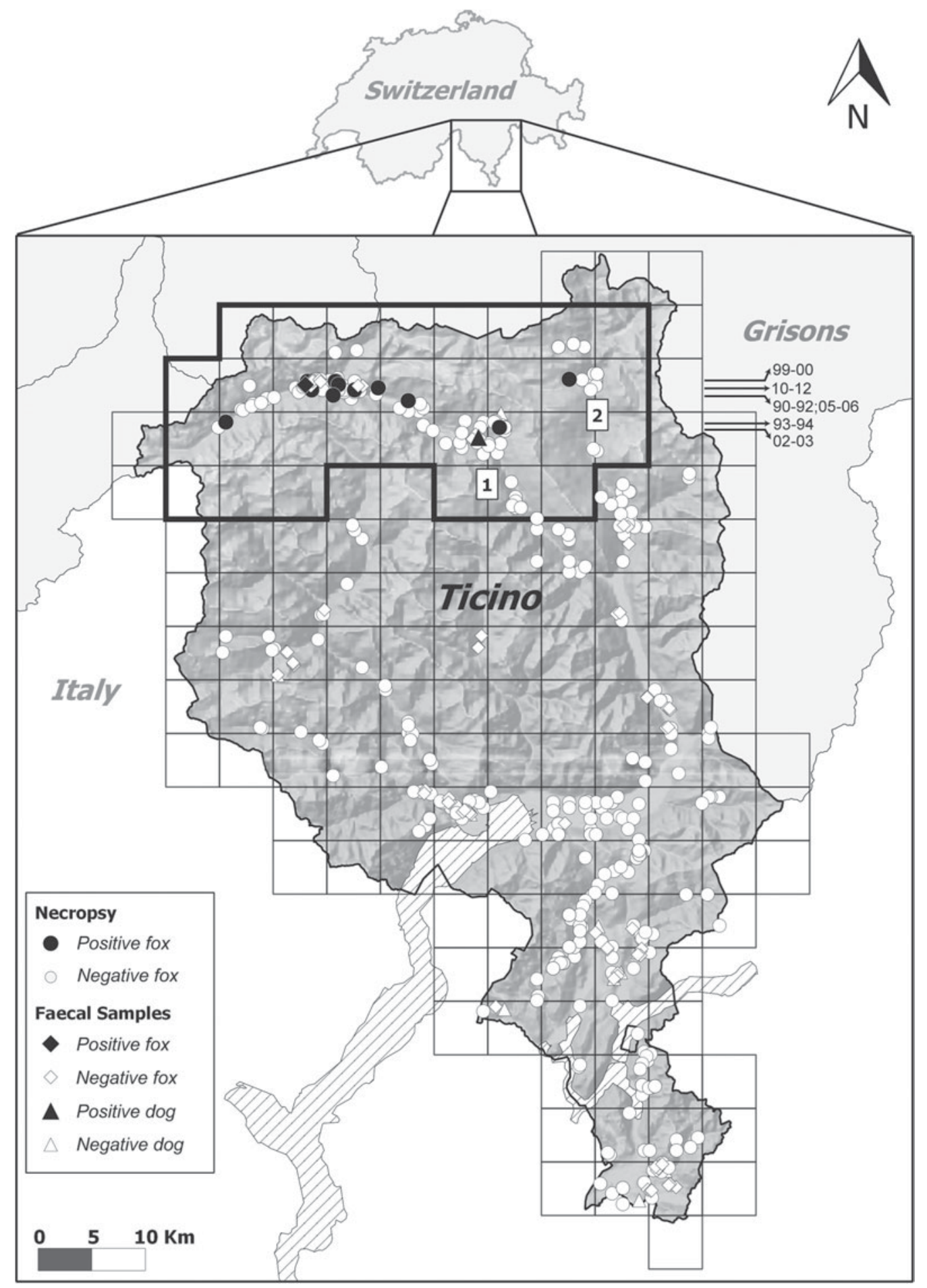

Fig. 2. Echinococcus multilocularis in foxes and dogs from the Canton of Ticino (southern Switzerland) between 1990 and 2012. Grid with $5 \times 5 \mathrm{~km}$ cells. The bold gridlines define the endemic area of E. multilocularis. 1 - Val Leventina; 2 - Valle di Blenio. The arrows in the upper right corner depict the latitude of the most southern case in a fox during each studied period.

The first E. multilocularis infections in foxes from Ticino were recorded more than 20 years ago (Ewald, 1993) but no autochthonous human cases have been documented in this region so far.

Autochthonous human AE was reported in two patients from South Tyrol between 1906 and 1922 (Hosemann et al. 1928) nearby the location of reported infections in foxes from northern Italy.
This may shed some light on the age and dynamics of these different alpine E. multilocularis foci that seem rather stable and not a result of a recent spread.

Rodent species distribution and fox predation on rodents

The analysis of the distribution areas of the vole species in Ticino gives evidence that $M$. arvalis is 


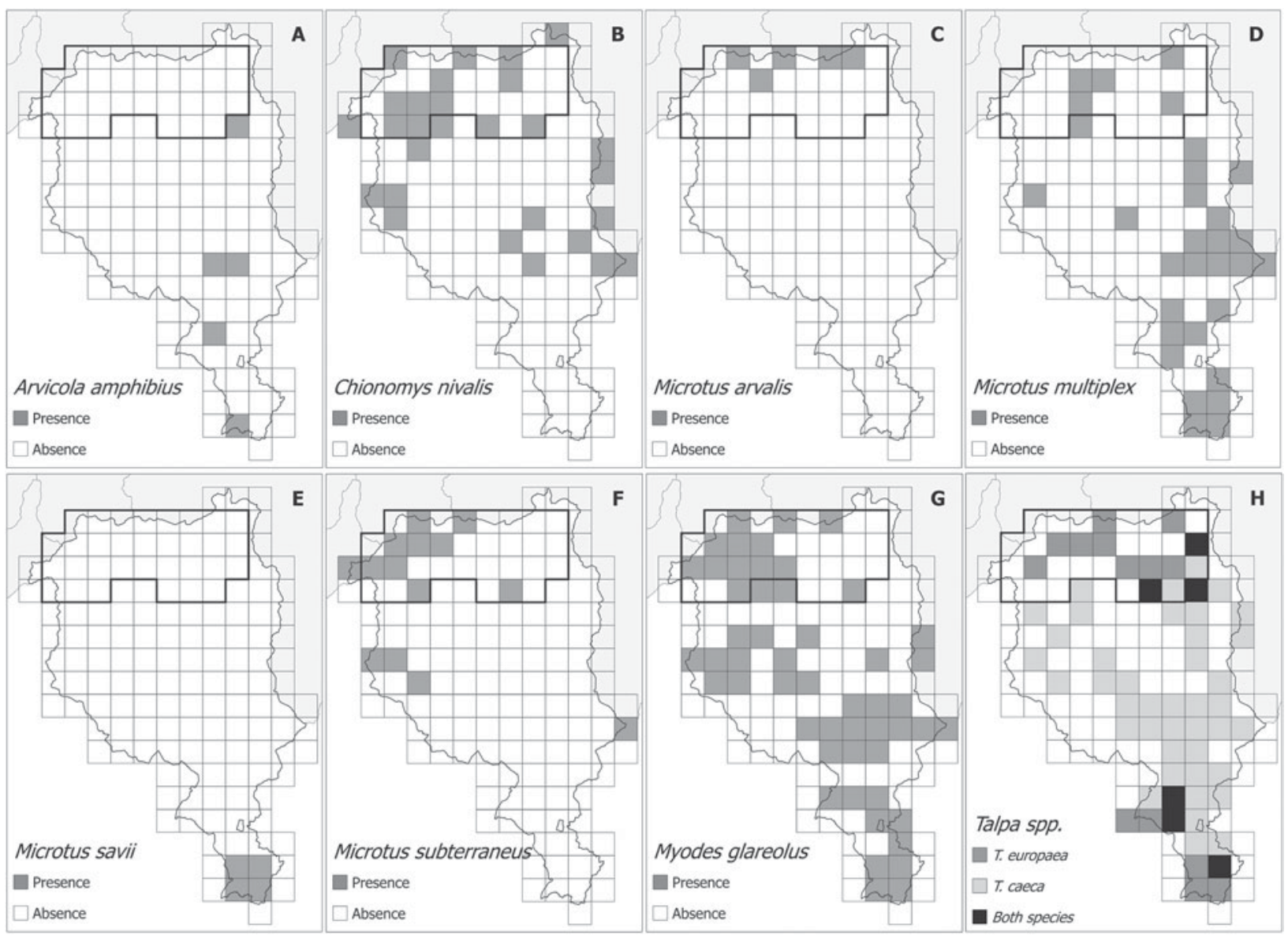

Fig. 3. Presence/absence of rodent $(A-G)$ and insectivore $(H)$ species in Ticino (Switzerland). Data obtained from the online cartographical server of the Swiss Biological Records Center (http://lepus.unine.ch/carto/). Grid with $5 \times 5 \mathrm{~km}$ cells. Bold gridlines define the endemic area for Echinococcus multilocularis in Ticino (see Fig. 2).

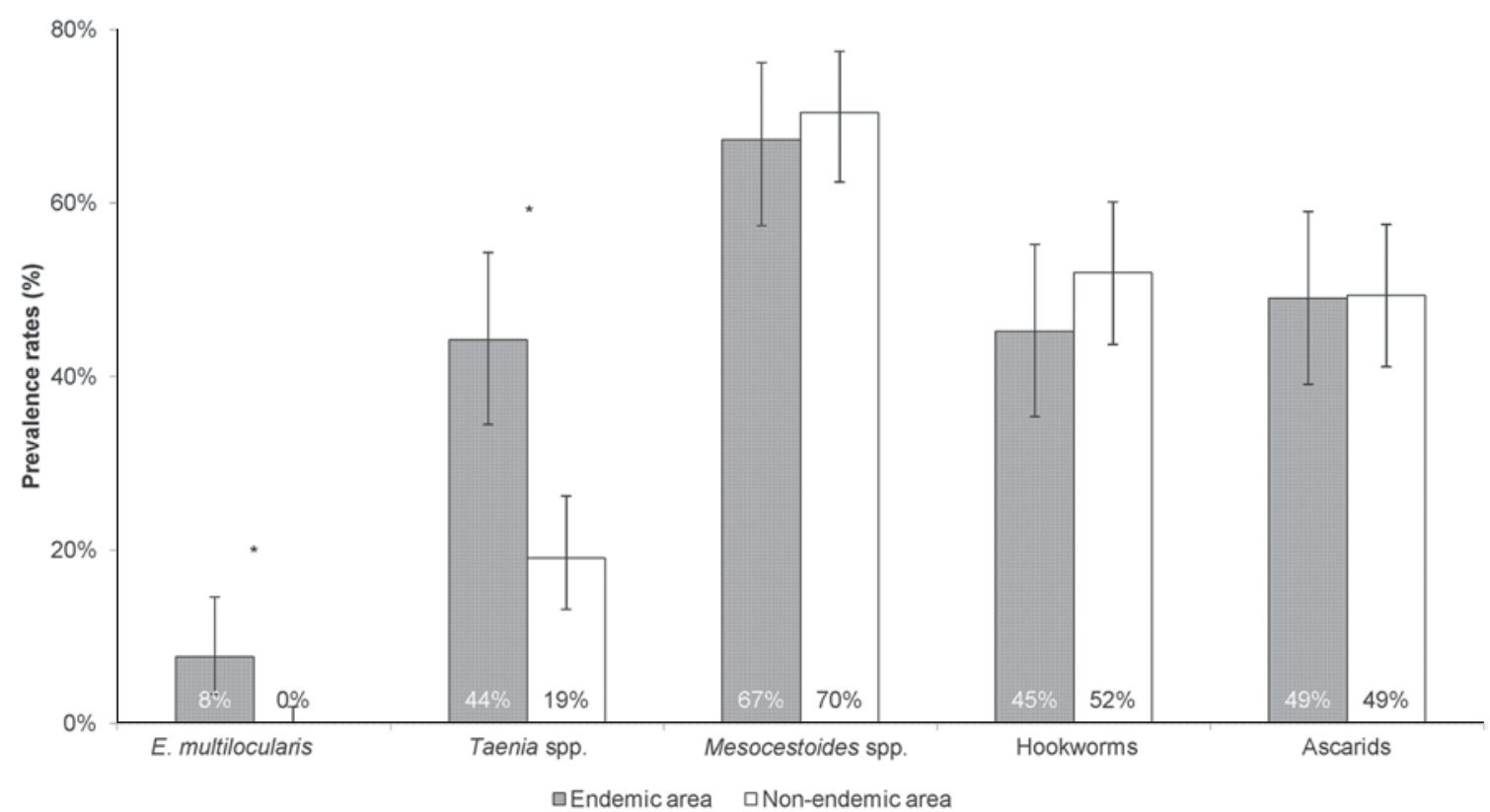

Fig. 4. Comparison of helminth prevalence rates between foxes from the Echinococcus multilocularis endemic $(n=104)$ and non-endemic $(n=152)$ areas in Ticino during 1999-2006. Asterisks: $P<0 \cdot 05$ (Chi-square test); error bars: $95 \%$ confidence interval. 
likely to act as the most important intermediate host for E. multilocularis in this Canton. Its apparent absence from the non-endemic area may be a limiting factor for the parasite's spread. Other rodent species present in both areas may also act as intermediate hosts. Microtus subterraneus is mostly found in the $E$. multilocularis endemic area but also in a few locations in the non-endemic area. There is a record of E. multilocularis infection in this species, i.e. one out of 169 necropsied specimens in France (Delattre et al. 1990), but no other extensive studies have been carried out so far. Although M. subterraneus is not a very abundant vole (Hausser, 1995), the number of foxes collected from these locations in the nonendemic area is too small to completely discard its relevance as an intermediate host. Conversely, $M$. glareolus, which has been described as a potential intermediate host for E. multilocularis (Bonnin et al. 1986; Stieger et al. 2002) has a distribution that is clearly unrelated to $E$. multilocularis infections in foxes. Maybe due to low densities or because they are not as important in foxes' diet, the presence of this and of the other rodent species in the non-endemic area seems to be insufficient to maintain the parasite's life cycle. The former species $A$. terrestris, an important intermediate host for $E$. multilocularis, has been reclassified into $A$. scherman and A. amphibius (Wilson and Reeder, 2005). Arvicola scherman, absent in Ticino, is abundant in E. multilocularis highly endemic areas. For example, in Zurich, Switzerland, high prevalence rates of infection (up to $40 \cdot 6-78 \cdot 5 \%$ in some areas) with fertile metacestodes (overall 9.3\%) have been documented in this species (Burlet et al. 2011). Interestingly, in our study A. amphibius was located exclusively in the E. multilocularis non-endemic area in Ticino. In contrast to $A$. scherman, this species reaches regions far outside the known endemic area of E. multilocularis in Europe. It is a semi-aquatic species associated with wetlands, rivers and ponds (Hausser, 1995) and this environment may protect it from fox predation. While A. scherman can be considered an important intermediate host, according to our study, the relevance of $A$. amphibius for the $E$. multilocularis life cycle in this region is questionable.

In the Massif Central, France, in an area of roughly $5000 \mathrm{~km}^{2}$, Deblock et al. (1988) defined a border between an endemic and a non-endemic area for $E$. multilocularis, based on the necropsies of foxes. This endemic area corresponded to locations where infected Arvicola sp. were previously recorded. Unfortunately, the authors did not describe the distribution of the other rodent species which derails possible relationships between the distribution of potential intermediate hosts and the observed pattern for E. multilocularis in foxes.

Another key factor to understand the role of different intermediate hosts in the parasite's life cycle is the fox predation rate. Foxes exhibit a dietary plasticity that is nonetheless related to a preference for certain prey (Macdonald, 1977; Hegglin et al. 2007). In Zurich, Switzerland, although burrow systems of $M$. arvalis were far less frequently recorded than the ones from A. scherman, the frequency of both species' remains in fox stomachs was similar (Hegglin et al. 2007). In other highly endemic areas for E. multilocularis in France, $M$. arvalis was the most common prey (Guislain et al. 2008) and foxes exhibited a predatory preference for it (Raoul et al. 2010). In the Müstair Valley, where no Arvicola species are recorded, E. multilocularis in foxes was likely associated with predation on Microtus species (Tanner et al. 2006). However, a study in western Switzerland showed that $A$. scherman can also be the most common prey of foxes (Weber and Aubry, 2009) and is likely to act as a key species for the parasite's transmission in certain areas. Unlike other less predated Arvicolids, A. scherman and $M$. arvalis are known agricultural pests. They inhabit meadows and pastures and develop pluriannual population cycles, reaching as many as 1000 and 2500 individuals ha ${ }^{-1}$, respectively (Hausser, 1995).

The analysis of other helminths' frequency in foxes may deliver some more information on their diet. Interestingly, Taenia spp. occurred more frequently in foxes from the $E$. multilocularis endemic area (Fig. 4). Taenia crassiceps and Taenia polyacantha are the most common Taenia species in foxes from Ticino (Ewald, 1993). Like E. multilocularis, both species have a dixenous life cycle, in which rodents are the most important intermediate hosts. Microtus arvalis is considered the most susceptible intermediate host for T. crassiceps (Rietschel, 1981) and is also an intermediate host for $T$. polyacantha (Jones and Pybus, 2001). In the Canton of Thurgau, Switzerland, a study on helminths of rodent species succeeded in finding both $T$. polyacantha and $T$. crassiceps in M. arvalis (Schaerer, 1987). There were significant differences between this species and $M$. glareolus, in which no infections were found. The higher number of Taenia spp. infections in the $E$. multilocularis endemic area may be related to the availability of susceptible intermediate hosts, such as $M$. arvalis, thus reinforcing its relevance in the foxes' diet and in the E. multilocularis life cycle. In contrast, helminths with life cycles not dependent on microtine species exhibited no spatial segregation.

\section{Limiting factors for the spread of $\mathrm{E}$. multilocularis}

Geographic barriers have been impacting the spread and distribution of rodents for a long time (Braaker and Heckel, 2009). After the Last Glacial Maximum (LGM), which took place more than 200000 years ago, animal and plant species were able to recolonize previously frozen regions (Sommer and Nadachowski, 2006). The current distribution of these species was strongly affected by the outcome of 
these events. The migration patterns of foxes and intermediate hosts after the LGM and the gradual colonization of different areas may help in the understanding of the current distribution of E. multilocularis and the patchy arrangement of infected foxes in the Alps. In a work by Braaker and Heckel (2009), mitochondrial DNA of different $M$. arvalis isolates revealed that the post-glaciation migrations of this species might have occurred upwards from Italy through the valleys of the bigger rivers in Switzerland. It is surprising to see that the postulated main routes of migration overlap with the valleys where E. multilocularis was found in Ticino (this paper) and in Grisons (Engadin and Bregaglia valleys) (Tanner et al. 2006). These findings seem to reinforce the hypothesis of $M$. arvalis relevance for E. multilocularis in these regions or at least reflect areas where the contact between definitive and intermediate hosts has occurred long enough to allow the establishment of a parasitic life cycle.

Analysis of the distribution of other species can help clarify the impact of geographic barriers. Talpa caeca and Talpa europaea are insectivores that often share the habitat with $M$. arvalis and $A$. terrestris (Giraudoux et al. 2003; Delattre et al. 2006). In Ticino, these two Talpa species have a segregated distribution (Fig. 3H). Maddalena et al. (2000) documented a clear border in Val Leventina, mostly due to geographic barriers. This border was set around latitude $46 \cdot 42^{\circ} \mathrm{N}$ coincident with the border of the endemic area for E. multilocularis obtained in the present study. Since $M$. arvalis is a grassland rodent, it is reasonable to assume that in Val Leventina the border features for the Talpa species would also be valid for $M$. arvalis, preventing it from spreading further south. If $M$. arvalis is the most important intermediate host for E. multilocularis in Ticino, its circumscription to the north of the canton would prevent the parasite from establishing on more southern areas where no key intermediate host is present.

Climatic variables in Ticino, such as temperature and rainfall, are distinct between the very northern mountain valleys and the more temperate lakeside pastures in the south. This north-south gradient in temperature and humidity could act as an adjuvant in balancing the stable epidemiological situation for E. multilocularis. However, as seen in Fig. 1, foxes have been found infected even in regions south from Ticino. This shows that climate is not per se an absolute exclusion factor for the distribution of the parasite in Europe and that other variables, such as the distribution of rodent communities, should be henceforth more frequently considered.

\section{ACKNOWLEDGEMENTS}

To Tiziano Maddalena, Simon Capt and Jürg Paul Müller for the valuable comments on the rodents' distribution in
Ticino. Also, to Laura Lurati for collecting part of the faecal samples and to Alexander Mathis for comments on the manuscript. This study represents the dissertation of Diogo Guerra, veterinarian.

\section{FINANCIAL SUPPORT}

This work was supported by the Federal Food Safety and Veterinary Office (FSVO) of Switzerland, by the EMIDA-ERA NET framework, and is within the scope of the EMIRO project 'The significance of rodent communities for the distribution of Echinococcus multilocularis: ecological and experimental investigations' (grant number 1.12.18 EMIDA EMIRO).

\section{REFERENCES}

Alther, P. (1996). Beitrag zur Epidemiologie und Diagnose der Echinococcus multilocularis - Infektion bei Endwirten. Vet Med thesis. University of Zurich, Zurich, Switzerland.

Berke, O., Romig, T. and von Keyserlingk, M. (2008). Emergence of Echinococcus multilocularis among red foxes in northern Germany, 1991-2005. Veterinary Parasitology 155, 319-322.

Bonnin, J., Delattre, P., Artois, M., Pascal, M., Aubert, M. and Petavy, A. (1986). Contribution à la connaissance des hôtes intermédiaires d'Echinococcus multilocularis dans le nord-est de la France. Annales de Parasitologie Humaine et Comparée 61, 235-243.

Braaker, S. and Heckel, G. (2009). Transalpine colonisation and partial phylogeographic erosion by dispersal in the common vole (Microtus arvalis). Molecular Ecology 18, 2518-2531.

Brossard, M., Andreutti, C. and Siegenthaler, M. (2007). Infection of red foxes with Echinococcus multilocularis in western Switzerland. Fournal of Helminthology 81, 369-376.

Bružinskaitè, R., Marcinkutè, A., Strupas, K., Sokolovas, V., Deplazes, P., Mathis, A., Eddi, C. and Šarkūnas, M. (2007). Alveolar echinococcosis, Lithuania. Emerging Infectious Diseases 13, 1618-1619.

Burlet, P., Deplazes, P. and Hegglin, D. (2011). Age, season and spatiotemporal factors affecting the prevalence of Echinococcus multilocularis and Taenia taeniaeformis in Arvicola terrestris. Parasites and Vectors 4, 1-9.

Casulli, A., Manfredi, M. T., La Rosa, G., Di Cerbo, A. R., Dinkel, A., Romig, T., Deplazes, P., Genchi, C. and Pozio, E. (2005). Echinococcus multilocularis in red foxes (Vulpes vulpes) of the Italian Alpine region: is there a focus of autochthonous transmission? International fournal for Parasitology 35, 1079-1083.

Casulli, A., Bart, J.M., Knapp, J., La Rosa, G., Dusher, G., Gottstein, B., Di Cerbo, A., Manfredi, M. T., Genchi, C., Piarroux, R. and Pozio, E. (2009). Multi-locus microsatellite analysis supports the hypothesis of an autochthonous focus of Echinococcus multilocularis in northern Italy. International fournal for Parasitology 39, 837-842.

Combes, B., Comte, S., Raton, V., Raoul, F., Boué, F., Umhang, G., Favier, S., Dunoyer, C., Woronoff, N. and Giraudoux, P. (2012). Westward spread of Echinococcus multilocularis in foxes, France, 2005-2010. Emerging Infectious Diseases 18, 2059-2062.

Deblock, S., Pétavy, A. F. and Gilot, B. (1988). Helminthes intestinaux du renard commun (Vulpes vulpes L.) dans le Massif central (France). Canadian Fournal of Zoology 66, 1562-1569.

Delattre, P., Giraudoux, P. and Quéré, J.-P. (1990). Conséquences épidémiologiques de la réceptivité d'un nouvel hôte intermédiaire du Taenia multiloculaire (Echinococcus multilocularis) et de la localisation spatiotemporelle des rongeurs infestés. Comptes rendus de l'Académie des Sciences 310, 339-344.

Delattre, P., Clarac, R., Melis, J.-P., Pleydell, D. and Giraudoux, P (2006). How moles contribute to colonization success of water voles in grassland: implications for control. Fournal of Applied Ecology 43, 353-359. Deplazes, P., Hegglin, D., Gloor, S. and Romig, T. (2004). Wilderness in the city: the urbanization of Echinococcus multilocularis. Trends in Parasitology 20, 77-84.

Di Cerbo, A. R., Manfredi, M. T., Trevisiol, K., Bregoli, M., Ferrari, N., Pirinesi, F. and Bazzoli, S. (2008). Intestinal helminth communities of the red fox (Vulpes vulpes L.) in the Italian Alps. Acta Parasitologica 53, 302-311.

Duscher, G., Pleydell, D., Prosl, H. and Joachim, A. (2006). Echinococcus multilocularis in Austrian foxes from 1991 until 2004. Fournal of Veterinary Medicine, Series B 53, 138-144. 
Eckert, J., Gemmell, M., Meslin, F. and Pawlowski, Z. (2001). WHO/ OIE Manual on Echinococcosis in Humans and Animals: A Public Health Problem of Global Concern, Vol. 32. World Organisation for Animal Health, Paris, France.

Eckert, J., Deplazes, P. and Kern, P. (2011). Alveolar echinococcosis (Echinococcus multilocularis) and neotropical forms of echinococcosis (Echinococcus vogeli and Echinococcus oligarthrus). In Oxford Textbook of Zoonoses: Biology, Clinical Practice, and Public Health Control, 2nd Edn (ed. Palmer, S. R., Soulsby, E. J. L., Torgerson, P. R. and Brown, D. W. G.), pp. 668-699. Oxford University Press, Oxford, UK.

Ewald, D. (1993). Prävalenz von Echinococcus multilocularis bei Rotfüchsen (Vulpes vulpes L.) in der Nord-, Ost- und Südschweiz sowie im Fürstentum Liechtenstein. Ph.D. thesis, Phil. II. University of Zurich, Zurich, Switzerland.

Fischer, C., Reperant, L., Weber, J., Hegglin, D. and Deplazes, P. (2005). Echinococcus multilocularis infections of rural, residential and urban foxes (Vulpes vulpes) in the canton of Geneva, Switzerland. Parasite 12, 339-346.

Genov, T., Svilenov, D. and Polyakova-Krusteva, O. (1980). The natural occurrence of Alveococcus multilocularis in the Microtus nivalis in Bulgaria. Doklady Bolgarskoi Akademii Nauk 33, 981-984.

Giraudoux, P., Craig, P., Delattre, P., Bao, G., Bartholomot, B., Harraga, S., Quéré, J., Raoul, F., Wang, Y. and Shi, D. (2003). Interactions between landscape changes and host communities can regulate Echinococcus multilocularis transmission. Parasitology 127, S121-S132.

Giraudoux, P., Raoul, F., Afonso, E., Ziadinov, I., Yang, Y., Li, L., Li, T., Quéré, J.-P., Feng, X. and Wang, Q. (2013a). Transmission ecosystems of Echinococcus multilocularis in China and Central Asia. Parasitology 140, 1655-1666.

Giraudoux, P., Raoul, F., Pleydell, D., Li, T., Han, X., Qiu, J., Xie, Y. Wang, H., Ito, A. and Craig, P.S. (2013b). Drivers of Echinococcus multilocularis transmission in china: small mammal diversity, landscape or climate? PLOS Neglected Tropical Diseases 7, e2045. doi: 10.1371/journal. pntd.0002045

Guislain, M.-H., Raoul, F., Giraudoux, P., Terrier, M.-E., Froment, G., Ferté, H. and Poulle, M.-L. (2008). Ecological and biological factors involved in the transmission of Echinococcus multilocularis in the French Ardennes. Fournal of Helminthology 82, 143-151.

Hansen, F., Jeltsch, F., Tackmann, K., Staubach, C. and Thulke, H.-H. (2004). Processes leading to a spatial aggregation of Echinococcus multilocularis in its natural intermediate host Microtus arvalis. International Fournal for Parasitology 34, 37-44.

Hausser, J. (1995). Säugetiere der Schweiz. Birkhauser, Basel, Switzerland. Hegglin, D., Bontadina, F., Contesse, P., Gloor, S. and Deplazes, P. (2007). Plasticity of predation behaviour as a putative driving force for parasite life-cycle dynamics: the case of urban foxes and Echinococcus multilocularis tapeworm. Functional Ecology 21, 552-560.

Hofer, S., Gloor, S., Muller, U., Mathis, A., Hegglin, D. and Deplazes, P. (2000). High prevalence of Echinococcus multilocularis in urban red foxes (Vulpes vulpes) and voles (Arvicola terrestris) in the city of Zurich, Switzerland. Parasitology 120, 135-142.

Hosemann, G., Schwarz, E., Lehmann, J. C. and Posselt, A. (1928). Die Echinokokken Krankheit. In Neue Deutsche Chirurgie, Vol. 40 (ed. Küttner, H.), pp. 103-107. Ferdinand Enke Verlag, Stuttgart, Germany. Houin, R., Deniau, M., Liance, M. and Puel, F. (1982). Arvicola terrestris, an intermediate host of Echinococcus multilocularis in France: epidemiological consequences. International Fournal for Parasitology 12, 593-600

Jones, A. and Pybus, M. J. (2001). Taeniasis and echinococcosis. In Parasitic Diseases of Wild Mammals (ed. Samuel, W. M., Pybus, M. J. and Kocan, K. K.), pp. 150-192. Iowa State University Press, Iowa, USA. Kharchenko, V. A., Kornyushin, V. V., Varodi, E. I. and Malega, O. M. (2008). Occurrence of Echinococcus multilocularis (Cestoda, Taeniidae) in red foxes (Vulpes vulpes) from Western Ukraine. Acta Parasitologica 53, $36-40$

Lind, E. O., Juremalm, M., Christensson, D., Widgren, S., Hallgren, G., Ågren, E., Uhlhorn, H. and Lindberg, A. (2011). First detection of Echinococcus multilocularis in Sweden, February to March 2011. Euro Surveillance 16, 696-705.

Macdonald, D. (1977). On food preference in the red fox. Mammal Review 7, 7-23.

Maddalena, T., Maurizio, R. and Moretti, M. (2000). Zone di contatto fra Talpa caeca Savi e Talpa europaea L. in Val Leventina, Valle di Blenio, Val Mesolcina, e Val San Giacomo (Cantoni Ticino e Grigioni, Svizzera / provicina di Sondrio, Italia). Bolletino dela Società Ticinese di Scienze Naturali 88, 13-18.

Magi, M., Macchioni, F., Dell'Omodarme, M., Prati, M., Calderini, P., Gabrielli, S., Iori, A. and Cancrini, G. (2009).
Endoparasites of red fox (Vulpes vulpes) in central Italy. Fournal of Wildlife Diseases 45, 881-885.

Manfredi, M., Genchi, C., Deplazes, P., Trevisiol, K. and Fraquelli, C. (2002). Echinococcus multilocularis infection in red foxes in Italy. Veterinary Record 150, 757.

Mathis, A., Deplazes, P. and Eckert, J. (1996). An improved test system for PCR-based specific detection of Echinococcus multilocularis eggs. Fournal of Helminthology 70, 219-222.

Meia, J.-S. and Weber, J.-M. (1995). Home ranges and movements of red foxes in central Europe: stability despite environmental changes. Canadian fournal of Zoology 73, 1960-1966.

Moks, E., Saarma, U. and Valdmann, H. (2005). Echinococcus multilocularis in Estonia. Emerging Infectious Diseases 11, 1973-1974.

Nonaka, N., Sano, T., Inoue, T., Teresa Armua, M., Fukui, D., Katakura, K. and Oku, Y. (2009). Multiplex PCR system for identifying the carnivore origins of faeces for an epidemiological study on Echinococcus multilocularis in Hokkaido, Japan. Parasitology Research 106 75-83.

Rajković-Janje, R., Marinculić, A., Bosnić, S., Benić, M., Vinković, B. and Mihaljević, ̌̌. (2002). Prevalence and seasonal distribution of helminth parasites in red foxes (Vulpes vulpes) from the Zagreb County (Croatia). Zeitschrift für Ұagdwissenschaft 48, 151-160.

Raoul, F., Deplazes, P., Rieffel, D., Lambert, J.-C. and Giraudoux, P. (2010). Predator dietary response to prey density variation and consequences for cestode transmission. Oecologia 164, 129-139.

Rataj, A. V., Bidovec, A., Žele, D. and Vengušt, G. (2010). Echinococcus multilocularis in the red fox (Vulpes vulpes) in Slovenia. European Fournal of Wildlife Research 56, 819-822.

Rausch, R. L. (1967). On the ecology and distribution of Echinococcus spp. (Cestoda: Taeniidae), and characteristics of their development in the intermediate host. Annales de Parasitologie Humaine et Comparée 42, 19-63.

Reperant, L., Hegglin, D., Fischer, C., Kohler, L., Weber, J.-M. and Deplazes, P. (2007). Influence of urbanization on the epidemiology of intestinal helminths of the red fox (Vulpes vulpes) in Geneva, Switzerland. Parasitology Research 101, 605-611.

Reperant, L., Hegglin, D., Tanner, I., Fischer, C. and Deplazes, P. (2009). Rodents as shared indicators for zoonotic parasites of carnivores in urban environments. Parasitology 136, 329-337.

Rietschel, G. (1981). Beitrag zur Kenntnis von Taenia crassiceps (Zeder, 1800) Rudolphi, 1810 (Cestoda, Taeniidae). Zeitschrift für Parasitenkunde 65, 309-315

Said-Ali, Z., Grenouillet, F., Knapp, J., Bresson-Hadni, S., Vuitton, D. A., Raoul, F., Richou, C., Millon, L. and Giraudoux, P. (2013). Detecting nested clusters of human alveolar echinococcosis. Parasitology 140, 1693-1700.

Schaerer, O. (1987). Die Metacestoden der Kleinsäuger (Insectivora und Rodentia) und ihre Wirtsarten Verbreitung und Häufigkeit im Kanton Thurgau (Schweiz). Ph.D. thesis, Phil. II. University of Zurich, Zurich, Switzerland. Schneider, R., Aspöck, H. and Auer, H. (2013). Unexpected increase of alveolar echinococcosis, Austria, 2011. Emerging Infectious Diseases 19, $475-477$.

Schweiger, A., Ammann, R. W., Candinas, D., Clavien, P.-A., Eckert, J., Gottstein, B., Halkic, N., Muellhaupt, B., Prinz, B. M., Reichen, J., Tarr, P. E., Torgerson, P. R. and Deplazes, P. (2007). Human alveolar echinococcosis after fox population increase, Switzerland. Emerging Infectious Diseases 13, 878-882.

Sikó, S. B., Deplazes, P., Ceica, C., Tivadar, C., Bogolin, I., Popescu, S. and Cozma, V. (2011). Echinococcus multilocularis in south-eastern Europe (Romania). Parasitology Research 108, 1093-1097.

Sommer, R. and Nadachowski, A. (2006). Glacial refugia of mammals in Europe: evidence from fossil records. Mammal Review 36, 251-265.

Sreter, T., Szell, Z., Egyed, Z. and Varga, I. (2003). Echinococcus multilocularis: an emerging pathogen in Hungary and Central Eastern Europe? Emerging Infectious Diseases 9, 384-386.

Staubach, C., Hoffmann, L., Schmid, V. J., Ziller, M., Tackmann, K. and Conraths, F. J. (2011). Bayesian space-time analysis of Echinococcus multilocularis-infections in foxes. Veterinary Parasitology 179, 77-83.

Štefanić, S., Shaikenov, B., Deplazes, P., Dinkel, A., Torgerson, P. and Mathis, A. (2004). Polymerase chain reaction for detection of patent infections of Echinococcus granulosus ("sheep strain") in naturally infected dogs. Parasitology Research 92, 347-351.

Stieger, C., Hegglin, D., Schwarzenbach, G., Mathis, A. and Deplazes, P. (2002). Spatial and temporal aspects of urban transmission of Echinococcus multilocularis. Parasitology 124, 631-640.

Takumi, K., de Vries, A., Chu, M. L., Mulder, J., Teunis, P. and van der Giessen, J. (2008). Evidence for an increasing presence of 
Echinococcus multilocularis in foxes in the Netherlands. International fournal for Parasitology 38, 571-578.

Tanner, F., Hegglin, D., Thoma, R., Brosi, G. and Deplazes, P. (2006). Echinococcus multilocularis in Grisons: distribution in foxes and presence of potential intermediate hosts. Schweizer Archiv fur Tierheilkunde 148 501-510.

Trachsel, D., Deplazes, P. and Mathis, A. (2007). Identification of taeniid eggs in the faeces from carnivores based on multiplex PCR using targets in mitochondrial DNA. Parasitology 134, 911-920.

Trewhella, W., Harris, S. and McAllister, F. (1988). Dispersa distance, home-range size and population density in the red fox (Vulpes vulpes): a quantitative analysis. Fournal of Applied Ecology 25, 423-434.
Van Gucht, S., Van Den Berge, K., Quataert, P., Verschelde, P. and Le Roux, I. (2010). No emergence of Echinococcus multilocularis in foxes in Flanders and Brussels anno 2007-2008. Zoonoses and Public Health 57 e65-e70.

Veit, P., Bilger, B., Schad, V., Schäfer, J., Frank, W. and Lucius, R. (1995). Influence of environmental factors on the infectivity of Echinococcus multilocularis eggs. Parasitology 110, 79-86.

Weber, J. M. and Aubry, S. (2009). Predation by foxes, Vulpes vulpes, on the fossorial form of the water vole, Arvicola terrestris scherman, in western Switzerland. Fournal of Zoology 229, 553-559.

Wilson, D. E. and Reeder, D. M. (2005). Mammal Species of the World: A Taxonomic and Geographic Reference, 3rd Edn. Johns Hopkins University Press, Baltimore, MD, USA. 